\title{
Making inter-disciplinary spaces for talk about and change in student writing and literacy development
}

\author{
Sherran Clarence \\ University of the Western Cape \\ sherranclarence@gmail.com
}

\begin{abstract}
This paper discusses the role of a Writing Centre in creating spaces for talk about and change in disciplinary writing pedagogy. It asks how collaborative partnerships between disciplinary academics and Writing Centre practitioners might be established and nurtured sustainably. Drawing on insights from two collaborations with academics in political studies and law, the article asserts that Writing Centre practitioners play a valuable role in talking about and changing the way academic writing and literacy is taught in the disciplines. This is shown by working consistently with the understanding that critical reading, thinking and writing are literacy acts rather than generic skills, and must therefore be learned and practiced in the disciplines. By supporting disciplinary academics in re-examining course outcomes, materials and assessments, and moving away from a 'skills approach' to writing, it is shown that building discipline-specific spaces for writing and literacy development is possible through these collaborative partnerships.
\end{abstract}

Keywords: academic literacy; collaborative partnerships; disciplinary writing; student writing development.

\section{Introduction}

This article seeks to contribute to a small but growing body of writing about Writing Centres in Southern Africa, and the work they are doing in these higher education environments. By examining two case studies, piloted in collaboration between disciplinary academics in two faculties or departments and the Writing Centre at the University of the Western Cape, this article asserts that Writing Centres can work in sustainable and creative ways to extend dialogues on writing and literacy pedagogy. Writing Centre practitioners can and should explore ways to collaborate and partner with disciplinary lecturers to create generative spaces for talking about and making visible the necessary teaching of academic writing and related literacies.

Academic writing is not a generic skill: it is, rather, a social and knowledge practice that is informed by the values and academic conventions of particular disciplines and the ways in which knowledge is constructed and disseminated by these disciplines (Lillis, 2001; Street, 2004; Archer, 2010). Understanding academic writing as a practice as opposed to a 'skill' allows us to move away from seeing student writing as an individual act done by an 'autonomous, socially neutral' person using language as a 'transparent medium of communication' where the meaning just has to be uncovered by the writer, and where literacy is 'universal' (Lillis, 2001: 31). Instead we can more accurately understand student writing as 'a social act' that uses language to make meaning and construct identity, and these acts are done in socio-historically contested academic spaces where literacies are 'numerous, varied and socially/institutionally situated' (Lillis, 2001: 31). 
Lea and Street, in their work on perceptions of writing in UK universities distinguish between three approaches to student writing in higher education: the study skills approach, where writing is treated as a generic skill, learnt outside of the disciplines and then transferred into them by the students; the academic socialisation approach, where students are inducted into the dominant discourses of the academy by knowledgeable experts and are expected to write like those experts to gain acceptance; and the academic literacies approach, where writing is seen a social practice, and part of contested space; where the writing itself is part of negotiating and constituting that space (Lea and Street, 1998; Jones, Turner and Street, 1999: $\mathrm{xx}$ ). Key in the latter approach is a view of the academy itself as constituted in and as a site of discourse and power (Street, 2004; Hermerschmidt, 1999). These three approaches are not discrete, and one does not move through them in a linear progression - rather, they encapsulate one another. Lillis (2001) also argues it is not meaningful to completely separate a 'skills approach' from other available ways of thinking about and teaching student writing; rather we need to realise a 'complex situation where there is often a coexistence, albeit of an unequal nature, of different approaches within the same pedagogic space'(163). However, in terms of the work I have been doing at UWC with students and with academic departments and disciplines, I am using Lea and Street's model, not to separate out any of these approaches, but to try and understand where some of the attitudes and ways of thinking about student writing and academic development may come from and what informs them. Moving from this understanding, I can better tailor my responses to these students and lecturers to work in more collaborative, open and constructive ways, and even work to shift our approach further towards an understanding of writing development indicated by the literacies approach. Like Lea and Street, though, I privilege the academic literacies approach because it expands on the previous two approaches, and offers a more 'encompassing understanding of the nature of student writing within institutional practices, power relations and identities' (1998: 2).

I think a great deal of academic development work in South African universities is aimed at academic socialisation. Many engagements around writing development I have been part of thus far indicate that we are working at the level of the skills and socialisation approaches. The socialisation approach has informed the two case studies this article reflects upon, and has shaped the collaboration with the academic lecturers in both Law and Political Studies. The central purpose of the work we have been doing for just over a year now in both partnerships, is to make the disciplinary conventions and expectations around writing more overt and understandable, and to find ways to explicitly teach students to shape their own writing according to these conventions and expectations. This has, importantly, moved us all beyond a view of academic writing as a discrete skill that can be taught outside of the content of the discipline, and has yielded very positive results for all three parties involved: the lecturers, the students and the Writing Centre. However, in the continuation phase of both of these collaborations, I am interested in starting sustained dialogues about ways in which we could aim to work towards an academic literacies approach to student writing development. There are many 'literacies' which students need to become familiar with in the academy (Gee 1994: xviii), and while becoming familiar with those literacies does indeed involve a degree of socialisation, there must also be space to question that assimilation and socialisation. Writing is an inherently social practice, and one cannot think about teaching it or doing it without also thinking about the context in which one teaches and writes, and the factors informing that context, such as 'complex intersections and inequalities of age, class, dis/ability, ethnicity, gender, race and sexuality' (Burke 2008: 200). Writing is a knowledge practice too, informed by the content that is being drawn on in the writing tasks, that influences the form and purpose of 
what is written. However, many disciplinary academics have become so inured in their disciplinary ways of knowing, thinking and writing that they may and do struggle to clarify their own disciplinary conventions and the expectations they have of their students' writingi. Thus, a sustainable way forward in student writing development could be found in partnerships between writing practitioners and academic lecturers, collaborating around student writing development and praxis.

\section{A Writing Centre in this context}

Before going into detail about the case studies, it is useful discuss in a little more detail the conception of a Writing Centre that informs the engagements reflected on in this paper. Writing Centres come in many different shapes and forms, and serve different purposes in higher education contexts around the world. Key to the focus of this paper are two elements: the first is the 'remedial space' in which Writing Centres have been and are located, their role as being there for the 'underprepared' students who were not able to meet the standards required of the academy, but were admitted because of a need to widen access to higher education (see North 1984; Ede, 1996; Boquet, 1999). Inherent in this framing and positioning of a Writing Centre is the conception of literacy as an autonomous model of literacy as a neutral set of skills divorced from any social context of practice (Carter 2009). The chief role of a Writing Centre, working within this discourse of autonomous literacy, is to facilitate students' mastery of these 'skills' so that they can produce more appropriate writing in the disciplines. This remedial space is one familiar to Writing Centres in South Africa as well, who have to contend with academics sending many non-mother tongue, less capable student-writers to the Writing Centre to have their work 'fixed' or 'polished' before handing it in. The second element is the resistance of Writing Centres against being framed in this marginalising and limiting way. Carter (2009) asks a pertinent question of how to resist being framed and marginalised by a remedial discourse based on an autonomous model of literacy that is the reason for most Writing Centres' existence; how to both socialise students into the academy and encourage critique and challenge of the socialisation process. The question then becomes how to manage the ambivalence inherent in our work, if indeed we have a 'dual allegiance to assimilation and liberation' (Gillam, quoted in Carter, 2009: 140).

A central element of both assimilation and liberation in Writing Centres is the 'talk' that happens there. North argues that the key to changing students' writing and developing their capacity as writers is 'talk in all its forms', and that these discussions with students about their writing is the 'essence of the writing center method' as it can model for students how to talk and think about their own writing (1984: 443). 'Writing centers are simply one manifestation polished and highly visible - of a dialogue about writing that is central to higher education' (North, 1984: 440). Carter echoes North in saying that 'talk' is the essence of writing centre work, but adds that a large part of this talk involves a paradox, as writing centres try to represent both students and the 'literacy demands of the academy', especially in their resistance to 'autonomous models of literacy' that control many rhetorical spaces over which the Writing Centres have no control or influence even. Thus, she argues that Writing Centres cannot simply engage with academics and other institutional parties outside of the Writing Centre and the discourses they draw on in their work, without recourse to language and terms, and discourses, which are already recognised as powerful. To some extent, our 'talk' has to be characterised and spoken of, at least initially, in their words, as such. However, there is a caution here about this 'talk' that is so valuable and central to Writing Centre work, with students, and with disciplinary 
academics. Grimm warns that rather than being 'liberatory' (as it is most often intended) this talk can be 'regulatory' and serve to normalise rather than question and examine more critically discourses around literacy that reveal the complexities of diversity in the academy (in Carter, 2009:140). Grimm and others demand a new kind of 'talk' based on their work - talk that changes institutional systems designed to 'force already marginalized students to change' rather than talk that changes these writers to fit the system without questioning the system at all (in Carter, 2009: 141). Some of the ideas of the purpose of this new kind of talk include positioning Writing Centre workers as change agents in writing pedagogy; changing the face of higher education through Writing Centre work, by exposing 'the limits of existing literacy practices in higher education' (Carter, 2009: 141).

The work with both students and academic lecturers reflected on in this paper is part of an ongoing process of exploring what kinds of talk are valuable and useful to both parties. In these two engagements, the quest is for increasing rhetorical dexterity, and increasing space to talk about, debate, and challenge our practices in teaching, and facilitating student access to, the literacies and ways of writing valued and practiced in the disciplines.

\section{The Case Studies}

In each of these cases, I will briefly describe the nature of the engagement and the role of writing in the discipline, and the observations and lessons drawn from the engagement. The two cases under consideration are the Politics Department, and the Law Faculty.

\section{The Politics Department}

\section{- Nature of engagement and the role of writing in the discipline}

The involvement with the Politics Department began in May 2009 after I was asked to work with them to support their first year students in essay writing. They indicated that a significant cause for the relatively low pass rates in recent years was many students' struggles to produce essays meeting the standards and conventions during term-time and examinations. They were very open to exploring and changing their teaching and tutoring practices around writing in particular to create a more supportive environment. In our discussions I aimed a significant part of my talk at questioning them on what writing was for in the discipline, and what they wanted to achieve. The overall aim was to create a more explicit and methodical induction of incoming students into the disciplinary academic practices of reading, thinking critically, and writing in the appropriate forms.

The discussions around improving student writing centred on the ability of students, by the end of first year, to be able to construct a clear, coherent and well-evidenced argument in response to an essay question. We unpacked what this would mean in terms of what kinds of writing and related reading and thinking exercises students would need to learn and practice throughout the year in order to complete this task. We also unpacked what would count as a clear, coherent and well-evidenced argument. These discussions resulted in an understanding that, in order to complete this essay writing task adequately by year-end, students would need to be guided through a clear reading and writing practice-process. It was decided that the ideal vehicle for this was the tutorial system, as the students could be reached in smaller groups, and more individual attention could be paid to students by trained tutors.

The first element of competent essay writing that was highlighted was the ability of students to read with understanding in order to make accurate and critical summaries of 
arguments posed in theoretical readings in the field, and in order to paraphrase and write using their own voice more evidently. The first-year lecturers thus devised a series of first term tutorial exercises that would give students repeated opportunities to read, discuss the arguments in the readings with a tutor, and then work on summarising and paraphrasing the main parts of those arguments, receiving feedback and guidance from the tutors on each exercise. These exercises were designed to build in, over the seven weeks of the first term, related practices like referencing.

The second term focused on a drafting and feedback process for the essay itself, which the department had not previously used. It was decided that instead of writing one essay per term without an opportunity to receive feedback and revise before submission, students would write one essay in the second term, and write a first and second draft. The tutors were then taken through the expectations of the drafting and rewriting process and coached on giving students useful and formative feedback on draft one. This was an important part of the overall shift in the teaching of writing in the first-year module, as it signalled a shift in the department's view of good essay writing. They moved beyond a view of good essay writing as the application of surface skills, like proper grammar, spelling and structure to an assigned topic, to one which views good essay writing as, at least, an epistemological practice which requires students to be explicitly and incrementally inducted into the disciplinary practices they are required to master. This shift can be seen in how the department is structuring the first year module for 2011, continuing to think about the assumptions made in the tasks given to students and the kinds of writing they are asking students to produce; in the ways in which tutors are selected and trained, as well as monitored and supported; and in their thinking about their own teaching practices.

\section{- Observations and lessons}

I will focus on two key observations related to the role of writing and the Writing Centre. The first observation refers to the two academics teaching on the module. Both have very different teaching styles. The one lends itself more towards a structured and incremental induction into the disciplinary discourses, and the other that is more entertaining and interesting to watch, but invites less participation and often assumes a level of competence in the discourse to which students have not yet been fully introduced. The lesson we drew from my observations of their teaching styles, linked with their desired outcomes for the module, is that it is important for the teachers to find out more about who their students are, and where they are in terms of their learning styles and needs, in order to create more responsive and structured lectures in the first semester especially. We also learnt, I think, to move beyond the notion of 'deficit' in the students. As we all moved through this project, the understanding grew that all students, regardless of their level of academic competence, need help understanding and negotiating the language and writing, as well as knowledge, demands of the discipline. An ongoing challenge for the lecturers remains how to structure the lectures and tutorials to provide a foundation for all students that does not leave the less able students confused and lost, and that excites the more able students sufficiently to keep them interested and engaged.

The second observation concerns the drafting and feedback process. This was the first year in which the department had allowed students to write a draft of their essay which the tutors read and commented on, before a final draft was revised and handed in for assessment. One interesting outcome from student survey data is the notion, among a few of the students 
who responded, that they did not like or want the drafting process. A few commented that it made them feel like 'bad writers' because they felt that good writers do not need to draft, but get it right the first time. There was also a comment that the drafting process made one student feel inadequate because it showed her where she had further thinking, reading and writing to do, and this undermined her self-confidence. I draw two possible lessons from this. One is that it is possible that the purpose and value of the drafting and feedback process is not being fully explained to the students. This could be mediated by having a session with the tutors ahead of the essay topic being handed out, clarifying the process for them so that they can do so for the students. Another is that there may be ways in which feedback is being given that seems more punitive and demoralising to some students, rather than encouraging and formative. This, too, can be mediated by spending more time with the tutors, marking work collectively and sharing comments and feedback in a workshop format, building their own confidence and capacity as tutors. This tutor training, in conjunction with the lecturers, who assess the final drafts, is such an important part of the talk around writing and literacy development referred to above. Part of this talk, from my perspective, is developing collective awareness about how we talk to students about their writing, and what we say. Lillis and Turner argue that many of the terms and concepts insiders to the disciplines use to talk about writing, like 'coherence' and 'argument' are not as clear and transparent to students as they are to us (2001). This leads to confusion and unnecessary frustration on both sides as students try to work out the opaque rules to writing in the discipline, and often fail to varying degrees. Part of this talk, too, is sharing with the department ways in which to model their disciplinary writing and related reading practices to students, as a way of 'talking' them into the discipline in very methodical and explicit ways (see Lillis, 2001: Ch 6).

\section{The Law Faculty}

\section{- $\quad$ Nature of engagement and the Role of writing in the discipline}

The Law Faculty at UWC is large, with over 600 students registered for first-year studies. The first-year lecturers, in 2010 and 2011, will be part of a research project funded by the University of Cape Town, looking at factors that affect student success in large classes. They decided to use the funding to focus on the development of students' writing ability, in particular their ability to construct more logical and well-substantiated legal opinions, a key writing task in first year. Their concern was to put in place firmer support and development of students' writing in first year, leading to more able student-writers in subsequent years of study.

I was brought into the project by the two lecturers spearheading it before the start of teaching, but after the project's inception, as a 'writing specialist', and we talked at length of how we could work together to embed the writing practices and skills students needed to master into the timetable and into the course content. Initially brought in as an advisor, we eventually decided that I would, with the lecturers' assistance in each of the four modules, design and facilitate twelve writing workshops over the course of the year, six per semester and three in each module. This actually became nine workshops in total in 2010, and will be 8 in total in 2011, due to time constraints. The idea behind the workshops was to spend roughly half of the one-hour long class talking about the writing expectations of the task, and how to work the content into the form required, and then allowing students to write a response to the given task to submit at the end of the hour. My role also involved supporting the tutors marking the 
written assignments with clear marking rubrics, and they were required to attend the workshops along with the lecturers.

Law students are required to write various types of documents, including case summaries, legal opinions and extended essay-type assignments. The focus of the writing done for assessment in first year is legal opinions and case summaries. Given the time constraints it was not possible to work on case summary writing, so we focused on the process of writing coherent and well-evidenced legal opinions. Basically, the lecturers had observed in previous years that students, even at the end of the year, were struggling to consider the law and apply it to the case at hand in a methodical, logical and appropriate way. The answers were either muddled and unclear, or missing vital information which rendered their conclusions either incorrect, unjustified or absent. Further, the first year lecturers struggled against firm criticism from second year lecturers, who argued that the students were not being taught to write 'properly'.

In the first semester the workshops focused on task analysis, a key part of the students' struggles to write appropriate answers to the task questions. Drawing on a task developed by Chirag Patel at the University of KwaZulu-Natal's Writing Place, I developed a worksheet designed to take students through a process of breaking down the question into content and direction, and then working out what they needed to find out to answer the question fully, in terms of issue under consideration, and the relevant key terms and legal principles. They then needed to write a structured response in class following the structure they had worked out in collaboration with me and the lecturer in the workshop. The tutors marked these assignments with clearly devised rubrics and guidance from me, giving brief but focused written feedback to students. We did three such tasks in the first semester, working from the principle of giving students repeated opportunities to practice disciplinary conventions as a means to mastering them eventually.

In the second semester we decided to move on from breaking the tasks down to building the written responses more explicitly. The workshop tasks focused on the writing process, assuming students could by then work out what the facts of the case were and what they needed to find out in order to draft an accurate and sensible opinion. We looked at how to state the issue, how to refer to the legal rules involved, and how then to apply that law to the case under consideration. We also tried to take students through discussions on the purpose of drafting opinions using this particular structure, as it is often easier for students to internalise the rules of the discipline when they understand what the rules are for. There were again three workshops focusing on this particular type of task over the course of the semester. In all workshops, the tasks were based on content that had been covered in class, and the lecturers concerned were present and often participated in the workshop to clarify facts, or add necessary guidance and information. Students were given marks for the exercises towards their class record to encourage attendance, which was high at all workshops.

\section{- Observations and lessons}

Again, I will focus on the writing development and the talk involved in these engagements with lecturers, tutors and students. There are two principle observations and lessons to relate here.

The first concerns my involvement in the assessment of the writing tasks completed in the workshops. Although I devised the rubrics, and gave the tutors guidance on how to assess 
the tasks, I did not play any role in monitoring the kind of feedback tutors were writing to students. This was partly due to the sheer volume of assignments (in excess of 600) and my own time constraints, and partly due to a decision made prior to my joining the project team about giving the task of assessing these assignments to two designated project tutors. The observation is that there is too much marking for two tutors to take on, and in terms of both time and form, they are not completely able to give the formative feedback necessary to meet the aims of the writing development workshops. In the first semester especially, students did not receive feedback on task one before they did task two and so on, and thus they did not see the kinds of improvements in their own writing that they were hoping for, and many found the process frustrating and demoralising, judging from initial survey data. A further problem was that, due to the same constraints, I did not read or assess any of the students' work myself. This led to a lack of understanding on my part of what the students were continuing to find difficult or challenging in the writing tasks, so that I could develop the workshop tasks to answer these concerns. I did receive feedback from lecturers and tutors which showed that there were definitely improvements in the structure of the written work, especially in mid-year tests and exams and again at year end, but this did not necessarily help me to be more responsive in my workshops, as they may not have been concerned with the same things I would have been looking for in terms of shifts in the students' writing. A lesson here is to spend more time at regular intervals talking to the tutors and lecturers about formative and guiding feedback, and modelling for them in collective marking workshops the kinds of feedback the lecturers and I would like to see students receiving, linked to the aims of the writing workshops we are developing. A further lesson is to read a representative sample of the writing being done in the workshops throughout the year, so as to design more responsive and truly developmental workshops in collaboration with the lecturers, who will also have a clearer understanding of how the students are progressing.

The second concerns the talk I have been engaging in with lecturers, tutors and students over the course of the year. Like Carter (2009) indicates, I certainly feel the need to develop rhetorical dexterity in my talk about my work from the Writing Centre and my reasons for working the way I choose to. I have found acquiring this dexterity in this particular project a real challenge. This is in part because I was brought into the project after its inception, and was not able to participate in the formative discussions around the project aims. The team had few ideas about how to develop the students' writing, but they had clear ideas about what the problems were that needed to be focused on. They framed the students' writing difficulties largely in terms of a deficit discourse, and from a skills approach, and were certainly hoping that the writing workshops would 'fix' many of these problems. In response, I had to think very carefully about what I could achieve in the workshops, and what my role should be, working as an outsider to the discipline, and unfamiliar with the disciplinary culture around talking, reading and writing about the law. This was a valuable process for me, but did create some tension in the first semester, as I tried to articulate my vision for the workshops, often against the very firm ideas held by the lecturers that I did not necessarily agree with. I found, as Carter suggests, that talking in my own terms and using the jargon of my discourses of academic literacy and writing development did little to convince the law lecturers of my point of view. However, I did meet with more success in the second semester, following a combination of students' improvement in the understanding of tasks shown in the written responses in tests and exams especially, and my own shift in approach towards my 'talk'.

I started to more consciously engage in talking about the aims and possibilities of the writing workshops using less specialised terms, and from an academic socialisation approach, 
taking account of the skills approach, but trying to move beyond it. At the end of 2010 we had reached a point where the lecturers involved see that it is far more beneficial for their students to learn how to write like disciplinary insiders from the inside, and not from the outside. Although, having said that, they have also noted the value an outsider can bring by making some of the opaqueness in the way questions are phrased and tasks are commented on more visible to both them and to the students and tutors. The lesson here, for 2011 at least, is to continue to grapple with the issue of how to talk and write students into the discipline in more explicit and supported ways. A further challenge is talking increasingly to the lecturers about possible changes to their teaching practice to allow more time for writing, talking and thinking in class, rather than outside of it in workshops and tutorials.

\section{Conclusions}

The more I talk with students, the tutors in the Writing Centre, and academic colleagues about student writing and its centrality and importance in teaching and learning, the more I realise that while much work has been done, much still has to be done. I continually ask myself why so much of the research into student writing published ten or more years ago is still current in terms of its claims and observations, and I think the answers lies with us, the people in the academy who uphold the ideals, values and practices that formed the landscape of our own tertiary education experiences. The many academic values, ideals and practices that create the culture of academia with which new students need to become familiar in order to succeed in higher education are part of us in ways that are not often clear to us. They are, in many ways, our 'ways of being' and we often do not stop to question them, or the way in which we work to uphold them (Bharuthram and McKenna, 2006). We often assume that our ways of knowing, and learning, talking, reading and writing about knowledge, are transparent and easily acquired by students, if they have met the required standards at secondary level. We seem to wrongly assume that students should come out of a secondary schooling system with 'tertiary literacy' (see Bock, 1988), and we are very quick to blame the secondary and even primary school system for tertiary students' failures to easily assimilate into the culture of higher education more broadly and the disciplinary fields more specifically.

It is not my aim here to lay blame, or to discover why so many students are struggling to succeed in higher education. It is my aim to argue that we need to spend more time making spaces to research, think and talk about the struggle to retain and graduate so many students in South African universities, and our roles in both creating and denying conditions for student retention and success. This is a significant part of my work with students and writing tutors in the Writing Centre, and with academic lecturers in the disciplines. I seek, in my talk with all of them, to move us all past a discourse of deficit and blame to create more open and truly collaborative spaces in which to explore the ways in which we can work together to create conditions for greater student retention and success through developing student-writers. This talk, as asserted by Stephen North in 1984, is a central part of Writing Centre work, and needs to be characterised, developed and even modelled for all people working with student-writers. Writing is central to learning, and teaching students to write about disciplinary knowledge can no longer be reasonably believed to be the sole province of academic support staff or Writing Centre peer-tutors or practitioners. Having made that claim, however, the engagements I have reflected on in this paper have shown me that while some academic lecturers may be very interested in working differently to teach their students how to write in the disciplines, they do not necessarily see how they can do this or believe they have the capacity. I think, for the present, this is where writing and academic literacy practitioners can enter into collaborative 
relationships that open spaces to talk about student writing in disciplines or departments, and begin to build from within the rhetorical dexterity we all need to talk about writing, and to change the ways in which we teach, assess and view student writing.

\section{References}

Archer, Arlene, 2010. 'Challenges and potentials for Writing Centres in South African tertiary institutions'. SAJHE, 24:4, 495-510.

Bharuthram, Sharita and Sioux McKenna. 2006. 'A writer-respondent intervention as a means of developing academic literacy', Teaching in Higher Education, 11:4, 495-507.

Bock, Hanne K. 1988. 'Academic literacy: Starting Point or Goal?' in Taylor, Gordon, Brigid Ballard, Vic Beasley, Hanne Bock, John Clanchy and Peggy Nightingale. 1988. Literacy by Degrees. Milton Keynes: Open University Press.

Boquet, Elizabeth H. 1999. "'Our Little Secret": A History of Writing Centers, Pre- to Post- Open Admissions'. College Composition and Communication, 50:3, 463-482.

Burke, Penny Jane. 2008. 'Writing, Power and Voice: Access to and Participation in Higher Education'. Changing English, 15:2, June, 199-210.

Carter, Shannon. 2009. 'The Writing Center Paradox: talk about Legitimacy and the Problem of Institutional Change'. College Composition and Communication, 61:1, 133-152.

Ede, Lisa. 1996. 'Writing Centers and the Politics of Location: A Response to Terrance Riley and Stephen M. North'. The Writing Center Journal, 16:2, Spring 1996, 111-130.

Gee, James Paul. 1994. 'Introduction', in Social Linguistics and Literacies. London: Routledge.

Hermerschmidt, Monika. 1999. 'Foregrounding background in academic learning', in Jones, C., Turner, J. and Street, B.V. 1999. Students writing in the university. Amsterdam: John Benjamins, 5-16.

Jacobs, Cecilia. 2007. Towards a critical understanding of the teaching of discipline-specific academic literacies: making the tacit explicit'. Journal of Education, 41: 2007, 1-24.

Jones, Carys, Joan Turner and Brian V. Street. 1999. 'Introduction', in Jones, C., Turner, J. and Street, B.V. 1999. Students writing in the university. Amsterdam: John Benjamins, xv-xxiv.

Lillis, Theresa M. 2001. Student Writing. Access, Regulation, Desire. London and New York: Routledge.

Lillis, Teresa M. and Joan Turner. 2001. Student Writing in Higher Education: contemporary confusion, traditional concerns. Teaching in Higher Education, 6:1, 57-67.

Lea, Mary and Brian V. Street. 1998. 'Student writing in higher education: An academic literacies approach', Studies in Higher Education, 23:2, 157-173.

North, Stephen M. 1984. 'The Idea of a Writing Center'. College English, 46:5, 433 - 446.

Street, Brian. 2004. 'Academic literacies and the "new orders": implications for research and practice in student writing in higher education'. Learning and Teaching in the Social Sciences, 1:1, 9-20. 
${ }^{\mathrm{i}}$ Sharita Bharuthram and Sioux McKenna(2006) comment on disciplinary academics often struggling to step outside of their disciplinary roles and 'headspaces' to consider the academic literacies that are embedded in their disciplinary teaching and writing. Cecilia Jacobs (2007) has also argued extensively for a need for collaboration between academic literacy practitioners and disciplinary academics in order to make the 'tacit' dimensions of learning and teaching more 'explicit'. 